Jurnal Keperawatan Silampari

Volume 3, Nomor 2, Juni 2020

e-ISSN: 2581-1975

p-ISSN: 2597-7482

DOI: https://doi.org/10.31539/jks.v3i2.1276

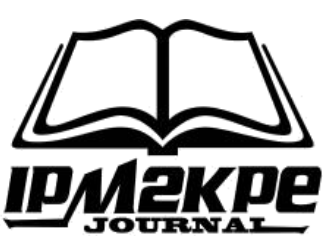

\title{
EMOSI DAN HUBUNGAN ANTAR SEBAYA PADA ANAK TUNALARAS USIA SEKOLAH ANTARA TERAPI MUSIK KLASIK (MOZART) DAN MURROTAL (SURAH AR-RAHMAN)
}

\author{
Padila $^{1}$, Setiawati ${ }^{2}$, In Inayah ${ }^{3}$, Henny Suzana Mediani $^{4}$, Chatarina Suryaningsih ${ }^{5}$ \\ Universitas Muhammadiyah Bengkulu ${ }^{1}$ \\ Sekolah Tinggi Ilmu Kesehatan Achmad Yani Bandung 2,3,5 \\ Universitas Padjadjaran $^{4}$ \\ padila@umb.ac.id ${ }^{1}$
}

\begin{abstract}
ABSTRAK
Penelitian ini bertujuan untuk menganalisis perbedaan efektivitas terapi musik klasik (mozart) dan terapi murrotal (surah ar-rahman) terhadap perubahan emosi dan hubungan antar sebaya pada anak tunalaras usia sekolah di SDN 1 Noman Musi Rawas Utara. Desain penelitian ini menggunakan kuasi-eksperimen, rancangan pre test and post test. Hasil penelitian terdapat perbedaan terapi musik klasik (mozart) dan murrotal (ar-rahman) terhadap perubahan emosi dan hubungan antar sebaya pada anak tunalaras. Terdapat perbedaan yang signifikan rerata tunalaras setelah diberikan intervensi klasik (mozart) minggu ke 5 yaitu 9,06 sedangkan setelah diberikan intervensi murrotal (Ar-Rahman) minggu ke 5 turun sampai 2,24. Rerata selisih skor tunalarasnya 6,82 kali, Simpulan, terapi murrotal (Ar-Rahman) 6-7 kali lebih cepat menurunkan emosional dan memperbaiki hubungan antar sebaya pada anak tunalaras dibandingkan terapi musik klasik (mozart).
\end{abstract}

Kata Kunci : Anak Tunalaras, Murrotal (Surah Ar-Rahman), Musik Klasik (Mozart)

\section{ABSTRACT}

This study aims to analyze the differences in the effectiveness of traditional music therapy (Mozart) and murrotal therapy (surah ar-Rahman) on emotional changes and peer relationships in school-aged children in SDN 1 Noman Musi Rawas Utara. The design of this study uses a quasi-experimental, pre-test, and post-test design. The results of the survey, there are differences in traditional music therapy (Mozart) and murrotal (arRahman) on emotional changes and peer relationships in children with disabilities. There was a significant difference in the mean tunalaras after being given the classic intervention (Mozart) week 5, which was 9.06. In contrast, after being given the murrotal intervention (Ar-Rahman) week 5, it fell to 2.24. the mean difference in the score of tunalaras was 6.82 times, Conclusions, Murrotal therapy (Ar-Rahman) 6-7 times faster to reduce emotionally and improve peer relations in children with tunalaras compared to traditional music therapy (Mozart).

Keywords: Tunalaras Children, Murrotal (Surah Ar-Rahman), Classical Music (Mozart) 


\section{PENDAHULUAN}

Masa usia sekolah, anak-anak belajar menguasai dan mengekspresikan emosi (Kustriyani et al., 2017). Usia 6-12 tahun anak-anak memahami konsep emosi yang lebih kompleks, seperti kecemburuan, kebanggaan, kesedihan dan kehilangan. anak-anak masih memiliki kesulitan didalam menafsirkan emosinya sehingga kejengkelan ataupun kemarahan karena orang tua atau guru bersikap pilih kasih, dan anak merasa ditelantarkan, akan diekspresikan dengan perilaku perlawanan agresif seperti memukul, mendorong, menentang dan berusaha mencelakai orang yang dianggap saingannya, ataupun sebaliknya diekspresikan dengan perilaku diam, suka menyendiri, tidak kooperatif, mudah nangis, mudah takut dan gemetar, sehingga dampaknya adalah anak akan mengalami penyimpangan emosional dan perilaku atau istilah resminya adalah anak Tunalaras (Sufriani, Sari, 2017).

Anak tunalaras dari beberapa sintesa menyatakan anak dengan gangguan emosi (emotional disturbunce), perilaku (behavior disorder), hiperaktivitas dan bermasalah dalam hubungan antar sebaya, yang berusia antara 6-17 tahun dengan karakteristik bahwa anak tersebut mengalami gangguan atau hambatan emosi dan berkelainan tingkah laku sehingga kuranga dapat menyesuaikan diri dengan baik terhadap lingkungan keluarga, sekolah, dan masyarakat tetapi masih dapat diajar untuk bersikap yang secara sosial dapat diterima dan secara pribadi menyenangkan (Ariffiani, 2017).

Hasil Penelitian Burhaein (2017) Secara umum menyatakan penyebab terjadinya tunalaras dapat diklasifikasikan menjadi dua, yaitu: (1) faktor penyebab bersifat internal, dan (2) bersifat eksternal. Penyebab internal adalah faktor-faktor yang langsung berkaitan dengan kondisi individu itu sendiri, seperti keturunan, kondisi fisik dan psikisnya. Sedangkan penyebab eksternal adalah faktor-faktor yang bersifat di luar individu terutama lingkungan, baik lingkungan keluarga, masyarakat, dan sekolah.

Dari hasil penelitian Sukeri (2018) menyimpulkan bahwa disfungsi kelenjar endokrin merupakan salah satu penyebab timbulnya kelainan emosi. Kelenjar endokrin ini mengeluarkan hormon yang mempengaruhi tenaga seseorang. Bila terus-menerus fungsinya mengalami gangguan, maka dapat berakibat terganggunya perkembangan fisik dan mental seseorang sehingga akan berpengaruh terhadap perkembangan emosinya.

Berdasarkan beberapa hasil penelitian menyimpulkan bahwa hampir semua anak yang mengalami perceraian orang tua mengalami masa peralihan yang sangat sulit. Orang tua yang sering berselisih paham dalam menerapkan peraturan atau disiplin dapat menimbulkan keraguan pada diri anak akan kebenaran suatu norma, sehingga anak akhirnya mencari jalan sendiri dan hal ini dapat menjadi awal dari terjadinya gangguan emosional (Arfi et al., 2019; Putri, 2018).

Beberapa aspek berkaitan dengan sekolah yang dapat menyebabkan terjadinya ketunalarasan antara lain tuntutan kurikulum yang tidak sesuai dengan tingkat perkembangan anak, hubungan antarteman sebaya yang kurang baik kurang perhatian guru tentang hal-hal yang bersifat positif dan konstruktif, seringnya guru yang memberikan perhatian hanya kepada anak-anak pintar dan mengabaikan mereka yang kurang pandai (Burhaein, 2017).

Salah satu bentuk terapi yang dapat digunakan dalam memberikan relaxsasi pada anak dengan gangguan emosi adalah dengan terapi musik dan mendengarkan murrotal Alqur'an, karena dengan adanya irama dapat menciptakan suasana yang menyenangkan, 
juga diketahui dapat mempengaruhi proses emosional, akademik, dan interaksi sosial (Fatima et al., 2018).

Penelitian Yang et al., (2018) menjelaskan bahwa Peranan Musik dalam pembelajaran dapat membantu kecepatan masuk nya informasi ke dalam otak dengan proses relaksasi, mediasi, pendengaran, visualisasi. Musik memicu keterkaitan yang lebih besar dari pada yang dapat diberikan oleh stimulus lainnya terhadap belahan otak sebelah kiri dengan yang kanan dan antara bidang-bidang di dalam otak yang bertanggung jawab atas emosi dan ingatan.

Hasil penelitian Nogaj (2020) menjelaskan bahwa penerapan terapi musik Mozart dapat menurunkan frekuensi kesulitan berperilaku dan meningkatkan kognitif pada siswa sekolah dasar. Selain terapi musik klasik mozart ada terapi alqur'an yang dapat dijadikan alternative yang aman dan telah terbukti efektif. Seperti Hasil penelitian Nuhan et al., (2018) terapi dengan alunan bacaan Al-Qur'an dengan stimulan murottal Al-Qur'an dapat dijadikan alternatif terapi baru sebagai terapi relaksasi, karena stimulan Al-Qur'an dapat memunculkan gelombang tetha sebesar 63,11\%. Dengan menggunakan Audio Ar-Rahman telah diteliti sebelumnya dan terbukti efektif menurunkan tingkat kecemasan, dan mampu membuat pasien menjadi relaksasi (Aziza et al., 2019).

Berdasarkan hal ini maka terapi musik klasik mozart dan murrotal surah Ar-Rahman perlu didengarkan kepada anak tunalaras yang mangalami masalah emosional dan hubungan dengan teman sebaya (Burhaein, 2017; Fatima et al., 2018; Kustriyani et al., 2017). Hal ini diperkuat pada pasien-pasien hipertensi, post operasi Caesar, dan pada anakanak dengan gangguan skizoprenia terbukti dengan cara mendengarkan musik, murrotal alqur'an yang iramanya teratur, lembut, mampu merelaksasikan mereka karena menstimulasi mekanisme koping individu menjadi lebih efektif (Cabaço et al., 2018).

Penelitian tentang terapi mozaik murottal sudah pernah dilakukan, tapi hanya menghubungkan 1 variabel saja dengan variabel lain. Namun penelitian ini membandingkan kedua terapi tersebut mana yang paling berpengaruh, selain itu penelitian ini juga lebih menekankan pada emosi dan hubungan antar sebaya.

\section{METODE PENELITIAN}

Penelitian ini menggunakan rancangan penelitian quasi eksperimen dengan menggunakan desain pretest dan posttest. Untuk mengukur pretest and posttest menggunakan uji t 2 sampel independent dan dependent. dimana uji t 2 sampel dependent digunakan untuk melihat apakah ada pengaruh pretest dan postest pada dua kelompok intervensi yang diberikan terapi musik mozart dan murrotal ar-rahman, sedangkan uji t 2 sampel independent digunakan untuk melihat apakah terdapat perbedaan hasil posttest pada perubahan emosi dan hubungan antar sebaya anak tunalaras antar dua kelompok intervensi. Teknik sampling yang digunakan adalah probability sampling dengan metode consecutive sampling. Sampel penelitian ini adalah anak yang mengalami gangguan emosional dan bermasalah dalam hubungan antar sebaya pada usia sekolah (10-11) tahun dengan jumlah sampel 34 anak terdiri atas 2 kelompok yaitu 17 anak intervensi terapi musik klasik (Mozart) dan 17 anak intervensi terapi murrotal (Ar-Rahman).

Penelitian ini dilaksanakan di Sekolah Dasar Negeri 1 Noman Kabupaten Musi rawas utara, dari tanggal 2 Febuari sampai dengan 6 maret 2019. Untuk mengukur hasil perlakuan terhadap anak tunalaras sebelum dan setelah intervensi menggunakan strength and 
difficulties questionnaire (SDQ) yang telah baku berisi 25 item pertanyaan dengan tiga kategori jawaban (0) : Tidak Pernah, (1) : Kadang-kadang, (2) : Sering, dalam kuesioner ini terdapat empat aspek yang bisa kita nilai dan itu merupakan satu kesatuan untuk mengukur masalah emosi dan hubungan antar sebaya pada anak usia sekolah yaitu masalah emosional, masalah perilaku, hiperaktivitas, dan masalah hubungan antar sesama.

\section{HASIL PENELITIAN} Analisa Univariat

Tabel.1

Distribusi Perubahan Emosi dan Hubungan Antar Sebaya pada Anak Tunalaras Sebelum dan Setelah Intervensi Terapi Musik Klasik (Mozart)

\begin{tabular}{lccccc}
\hline Variabel & $\begin{array}{c}\text { Mean } \\
\text { Median }\end{array}$ & SD & $\begin{array}{c}\text { Minimal- } \\
\text { Maksimal }\end{array}$ & 95\% CI & $\begin{array}{c}\text { Total selisih Means } \\
\text { pre-post 5 }\end{array}$ \\
\hline Pretest & 26,35 & 4,5 & $18-36$ & $24,05-28,65$ & \\
Postest 1 & 26 & & & & \\
& 26,71 & 4,2 & $17-34$ & $24,56-28,85$ & \\
Postest 2 & 26,84 & & & & $16,31-18,27$ \\
Postest 3 & 26,29 & 4,9 & $17-36$ & $23,74-28,84$ & \\
& 26 & & & & \\
Postest 4 & 15,06 & 4,9 & $10-26$ & $12,53-17,59$ & \\
& 13 & & & & \\
Postest 5 & 13,53 & 3,1 & $10-20$ & $11,91-15,15$ & \\
& 13 & & & & \\
\hline
\end{tabular}

Sumber: Data Primer yang sudah diolah (2020)

Berdasarkan tabel 1 dengan memperhatikan hasil pada pretest dan posttest intervensi terapi musik klasik (mozart) didapatkan nilai rata-rata pretest 26,35 , median 26,00 , (95\% CI $=24,05-28,65)$ dengan SD 4,5, nilai pretest terendah 18 dan tertinggi 36. Dari hasil estimasi interval disimpulkan bahwa 95\% diyakini bahwa rerata perubahan emosi dan hubungan antar sebaya pada anak tunalaras sebelum intervensi terapi musik klasik mozart adalah $24,05-28,65$.

Berdasarkan tabel 1 dengan memperhatikan hasil pada postest ke 5 intervensi terapi musik klasik (mozart) didapatkan nilai rata-rata postest 9,06, median 8,00, $(95 \% \mathrm{CI}=7,74$ 10,38) dengan SD 2,6, nilai postest terendah 3 dan tertinggi 13. Dari hasil estimasi interval disimpulkan bahwa 95\% diyakini bahwa rata-rata postest perubahan emosi dan hubungan antar sebaya pada anak tunalaras dengan kelompok intervensi terapi musik klasik mozart adalah 7,74-10,38.

Dari hasil estimasi interval disimpulkan bahwa 95\% diyakini bahwa rerata perubahan emosi dan hubungan antar sebaya pada anak tunalaras sebelum intervensi terapi musik klasik mozart adalah 24,05 - 28,65, dan setelah dilakukan terapi musik pada posttest ke 5 menjadi 7,74-10,38 terlihat selisih menurunnya rerata sebanyak 16,31 -18,27. 
Tabel.2

Distribusi Perubahan Emosi dan Hubungan Antar Sebaya pada Anak Tunalaras Sebelum dan Setelah Intervensi Terapi Musik Murrotal (Surah Ar-Rahman)

\begin{tabular}{|c|c|c|c|c|c|}
\hline Variabel & $\begin{array}{l}\text { Mean } \\
\text { Median }\end{array}$ & SD & $\begin{array}{l}\text { Minimal- } \\
\text { Maksimal }\end{array}$ & $95 \% \mathrm{CI}$ & $\begin{array}{c}\text { Total Selisih } \\
\text { Means pre- } \\
\text { post } 5\end{array}$ \\
\hline Pretest & $\begin{array}{c}25,71 \\
25\end{array}$ & 3,7 & $18-32$ & $23,78-27,63$ & \\
\hline Postest 1 & $\begin{array}{c}25,06 \\
24\end{array}$ & 3,6 & $15-37$ & $21,83-28,29$ & \\
\hline Postest 2 & $\begin{array}{c}27,41 \\
29\end{array}$ & 4,9 & $21-33$ & $25,57-29,26$ & $22,37-24,57$ \\
\hline Postest 3 & $\begin{array}{c}12,82 \\
11\end{array}$ & 4,1 & $6-19$ & $10,73-14,92$ & \\
\hline Postest 4 & $\begin{array}{c}11,82 \\
11\end{array}$ & 4,1 & $4-17$ & $9,72-13,93$ & \\
\hline Postest 5 & $\begin{array}{c}2,24 \\
2\end{array}$ & 1,6 & $0-5$ & $1,41-3,06$ & \\
\hline
\end{tabular}

Sumber: Data Primer yang sudah diolah (2020)

Berdasarkan tabel 2 dengan memperhatikan hasil distribusi nilai pada pre test dan post test intervensi terapi murrotal (ar-rahman) didapatkan rata-rata tunalaras pretest 25,71, median 25,00, (95\% CI = 23,78-27,63) dengan SD 3,7, nilai skor pretest tunalaras terendah 18 dan tertinggi 32. Dari hasil estimasi interval disimpulkan bahwa 95\% diyakini bahwa rata-rata pretest perubahan emosi dan hubungan antar sebaya pada anak tunalaras dengan kelompok intervensi terapi murrotal (ar-rahman) adalah 23,78-27,63.

Berdasarkan tabel 2 dengan memperhatikan hasil distribusi nilai pada postest ke 5 setelah intervensi terapi murrotal (ar-rahman) didapatkan rata-rata posttest tunalaras 2,24, median 2, (95\% CI = 1,41-3,06) dengan SD 1,6, nilai skor postest terendah 0 dan tertinggi 5. Dari hasil estimasi interval disimpulkan bahwa $95 \%$ diyakini bahwa rata-rata postest perubahan emosi dan hubungan antar sebaya pada anak tunalaras dengan kelompok intervensi terapi murrotal (ar-rahman) adalah 1,41 - 3,06.

Dari hasil estimasi interval disimpulkan bahwa $95 \%$ diyakini bahwa rerata perubahan emosi dan hubungan antar sebaya pada sebelum intervensi terapi musik murrotal (arrahman) adalah 23,78 - 27,63, dan setelah dilakukan terapi musik pada posttest ke 5 menjadi 1,41-3,06 terlihat selisih menurunnya sebanyak 22,37 -24,57.

Tabel. 3

Hasil Homogenitas Varians pada Perubahan Emosi dan Hubungan Antar Sebaya anak Tunalaras Kelompok Intervensi Terapi Musik Klasik (Mozart) dan Terapi Murrotal (Surah ar-Rahman)

\begin{tabular}{lccc}
\hline Variabel & & Levene's test & Hasil uji homogenitas varians \\
\hline $\begin{array}{l}\text { Pretest- } \\
\text { Protest }\end{array}$ & Equal $\begin{array}{c}\text { variances } \\
\text { assumed } \\
\text { Equaliances not } \\
\text { assumed }\end{array}$ & 0,68 & Homogen \\
\hline
\end{tabular}

Sumber: Data Primer yang sudah diolah (2020) 
Berdasarkan tabel 3 memperlihatkan bahwa hasil uji homogenitas varians dengan menggunakan uji levene's test diatas menghasilkan nilai $\mathrm{p}=0,068>0,05$ artinya dapat disimpulkan bahwa variasi kedua kelompok intervensi baik kelompok terapi musik klasik (mozart) dan terapi murrotal (ar-rahman) sama atau disebut Homogen.

\section{Analisa Bivariat}

Tabel. 4

Hasil Uji Perbedaan Sebelum dan Setelah

Terapi Musik Klasik (Mozart)

\begin{tabular}{cccc}
\hline & Variabel & Sig. (2-tailed) & Uji statistik \\
\hline Pair 1 & Pretest--Postest 1 & .783 & \\
Pair 2 & Pretest - Postest 2 & .962 & Paired t test dengan uji t 2 \\
Pair 3 & Pretest - Postest 3 & .000 & sampel dependen \\
Pair 4 & Pretest - Postest 4 & .000 & \\
Pair 5 & Pretest - Postest 5 & .000 & \\
\hline
\end{tabular}

Sumber: Data Primer yang sudah diolah (2020)

Berdasarkan tabel 4 memperlihatkan bahwa hasil uji $2 \mathrm{t}$ dependent terapi musik klasik (mozart) dari hasil analisis "paired sample statistics" terlihat perbedaan nilai p yang dapat dilihat pada kolom sig (2-tailed). Jika nilai $\mathrm{p}<0,05$ maka kesimpulannya : ada perbedaan yang signifikan rata-rata pretest dan posttest anak tunalaras.

Berdasarkan tabel 4 hasil pretest-postest 1 nilai $\mathrm{p}=0,783$ dan hasil pretest-postest 2 nilai $\mathrm{p}$ : 0,962 maka dapat disimpulkan hasil nilai $\mathrm{p}$ nya $>0,05$ artinya tidak ada perbedaan yang signifikan rata-rata pretest dan posttest ke 1 dan 2 anak tunalaras kelompok klasik Mozart, Sedangkan Hasil pretest-postest ke 3, 4 dan 5 nilai $\mathrm{p}=0,00$, Maka dapat disimpulkan hasil nilai $\mathrm{p}$ nya $<0,05$ artinya ada perbedaan yang signifikan rata-rata pretest dan posttest ke 3, 4 dan 5 pada perubahan emosi dan hubungan antar sebaya anak tunalaras kelompok klasik mozart.

Tabel. 5

Hasil Uji Perbedaan Perubahan Emosi dan Hubungan Antar Sebaya Anak Tunalaras Sebelum dan Setelah Terapi Murrotal (Ar-rahman)

\begin{tabular}{llll}
\hline & Variabel & Sig. (2-tailed) & Uji statistik \\
\hline Pair 1 & Pretest -- Postest 1 & .642 & \\
Pair 2 & Pretest - Postest 2 & .177 & Paired t test dengan uji t 2 \\
Pair 3 & Pretest - Postest 3 & .000 & sampel dependen \\
Pair 4 & Pretest - Postest 4 & .000 & \\
Pair 5 & Pretest - Postest 5 & .000 & \\
\multicolumn{2}{l}{ Sumber: Data Primer yang sudah diolah (2020) }
\end{tabular}

Sumber: Data Primer yang sudah diolah (2020)

Berdasarkan tabel 5 memperlihatkan bahwa hasil uji $2 \mathrm{t}$ dependent terapi musik murrotal (ar-rahman) hasil pretest-postest 1 nilai $\mathrm{p}$-value $=0,642$ dan hasil pretest-postest 2 nilai p-value : 0,177 maka dapat disimpulkan hasil nilai $\mathrm{p}$ nya $>0,05$ artinya tidak ada perbedaan yang signifikan rata-rata pretest dan posttest ke 1 dan 2 anak tunalaras kelompok 
murrotal ar-rahman sedangkan hasil pretest-postest 3, 4 dan 5 nilai p-valuenya $=0,000$. Maka dapat disimpulkan hasil nilai $\mathrm{p}$ nya $<0,05$ artinya ada perbedaan yang signifikan rata-rata pretest dan posttest ke 3,4 dan 5 pada perubahan emosi dan hubungan antar sebaya anak tunalaras kelompok murrotal ar-rahman.

Tabel.6

Hasil Uji Perbedaan Perubahan Emosi dan Hubungan Antar Sebaya Anak Tunalaras Setelah Diberikan Terapi Musik pada Kedua Kelompok Intervensi

\begin{tabular}{lcccc}
\hline & Variabel & N & Sig. (2-tailed) & Uji statistik \\
\hline Postest 1 & Murrotal & 17 & 25,06 & \\
& Mozart & 17 & 26,71 & \\
Postest 2 & Murrotal & 17 & 27,41 & \\
& Mozart & 17 & 26,29 & Uji t 2 sampel \\
Postest 3 & Murrotal & 17 & 12,82 & independent \\
& Mozart & 17 & 15,06 & \\
Postest 4 & Murrotal & 17 & 11,82 & \\
& Mozart & 17 & 13,53 & \\
Postest 5 & Murrotal & 17 & 2,24 & \\
& Mozart & 17 & 9,06 & \\
\hline
\end{tabular}

Sumber: Data Primer yang sudah diolah (2020)

Berdasarkan tabel 6 Dari hasil penelitian setelah diberikan terapi musik pada kedua kelompok dapat dilihat pada hasil postest ke 5 antara terapi murrotal (ar-rahman) dan terapi music klasik (mozart) didapatkan nilai rata-rata 2,24 dan 9,06. Semakin kecil hasil nilai rerata pada kedua kelompok setelah intervensi menunjukkan semakin menurunnya kejadian tunalaras pada anak, dari hasil posttest murrotal ke 5 nilai reratanya lebih kecil dari klasik (mozart) artinya ada perbedaan yang signifikan rerata perubahan emosi dan hubungan antar sebaya anak tunalaras setelah diberikan intervensi terapi murrotal (ar-rahman) skor tunalaras pada anak jauh lebih menurun dari pada terapi musik klasik (Mozart).

\section{PEMBAHASAN}

Berdasarkan tabel 1 menunjukkan bahwa rerata perubahan emosi dan hubungan antar sebaya pada anak tunalaras sebelum intervensi terapi musik klasik mozart adalah 24,05 28,65, dan setelah dilakukan terapi musik pada posttest ke 5 menjadi 7,74-10,38 terlihat selisih menurunnya rerata sebanyak 16,31 -18,27.

Menurut Nogaj (2020) musik klasik yang slow mempunyai fungsi menenangkan pikiran dan katarsis emosi, serta dapat mengoptimalkan tempo, ritme, melodi dan harmoni yang teratur sehingga menghasilkan gelombang alfa serat gelombang tetha dalam gendang telinga sehingga memberikan efek menenangkan yang membuat otak siap menerima masukan baru, rileks, dan menidurkan, sehingga terapi music klasik (mozart) bisa digunakan pada anak yang mengalami gangguan emosional.

Hasil penelitian diatas selaras dengan penelitian Ilari et al., (2020) yang menjelaskan bahwa ada pengaruh setelah intervensi musik klasik terhadap perubahan perilaku anak, Hal ini dijelaskan karena fungsi otak dengan kemampuan menyimpan hasil stimulasi sehingga mempengaruhi proses atau produk dimana pengetahuan, pikiran, aktivitas mental dan mengingat berbagai informasi yang disampaikan dari musik serta berperan sebagai 
perangsang yang kaya motif untuk perkembangan perilakunya. Sedangkan pengaruh musik untuk kecerdasan emosi adalah kecerdasan untuk kita mengerti diri sendiri yang berkaitan dengan perasaan, karena musik adalah suatu pesan yang berisi syair, nada irama yang dapat meningkatkan kecerdasan emosional.

Berdasarkan tabel 2 dengan memperhatikan hasil distribusi nilai pada pre test dan post test intervensi terapi murrotal (ar-rahman) didapatkan rata-rata tunalaras pretest 25,71, median 25,00, (95\% CI = 23,78-27,63) dengan SD 3,7, nilai skor pretest tunalaras terendah 18 dan tertinggi 32. Dari hasil estimasi interval disimpulkan bahwa $95 \%$ diyakini bahwa rata-rata pretest perubahan emosi dan hubungan antar sebaya pada anak tunalaras dengan kelompok intervensi terapi murrotal (ar-rahman) adalah 23,78 - 27,63.

Berdasarkan tabel 2 dengan memperhatikan hasil distribusi nilai pada postest ke 5 setelah intervensi terapi murrotal (ar-rahman) didapatkan rata-rata posttest tunalaras 2,24, median 2, (95\% CI = 1,41-3,06) dengan SD 1,6, nilai skor postest terendah 0 dan tertinggi 5. Dari hasil estimasi interval disimpulkan bahwa $95 \%$ diyakini bahwa rata-rata postest perubahan emosi dan hubungan antar sebaya pada anak tunalaras dengan kelompok intervensi terapi murrotal (ar-rahman) adalah 1,41 - 3,06.

Dari hasil estimasi interval disimpulkan bahwa $95 \%$ diyakini bahwa rerata perubahan emosi dan hubungan antar sebaya pada sebelum intervensi terapi musik murrotal (arrahman) adalah 23,78 - 27,63, dan setelah dilakukan terapi musik pada posttest ke 5 menjadi 1,41-3,06 terlihat selisih menurunnya sebanyak 22,37 -24,57.

Menurut Nurqolbi, Kamaruddin, (2019) yang menjelaskan bahwa Al-Quran memiliki banyak manfaat bagi pembaca maupun pendengar salah satunya terhadap perkembangan emosional, interaksi dan kognitif yaitu dapat membuat pendengarnya merasa tentram, tenang, nyaman, mempertajam ingatan dan pemikiran yang cemerlang. Terapi murottal AlQur'an juga menjadi bagian dari terapi musik (karena murottal Al-Qur'an dapat diartikan sebagai rekaman suara Al-Qur'an yang dilagukan oleh seorang Qori' (pembaca Al-Qur'an). Murottal Al-Qur'an juga menjadi terapi spiritualitas karena membuat individu mengingat Allah SWT. Kepercayaan spiritual memainkan peranan penting dalam mengahadapi kecemasan, ketakutan, dan rasa keputusasaan.

Diperkuat oleh Astuti et al., (2017) ketika seseorang mendengarkan alunan alqur'an yang lembut, sinyal itu akan ditangkap oleh daun telinga. Selanjutnya impuls bacaan akan diteruskan sampai ke talamus (bagian batang otak). Bila seseorang memahami bahasa atau maknanya, impuls akan diteruskan ke area auditorik primer dan sekunder, lalu diolah di area wernicke untuk diinterpretasikan makna-maknanya. Kemudian, impuls akan diasosiasikan ke area prefrontalagar terjadi perluasan pemikiran atau pendalaman makna yang turut berperan dalam menetukan respon hipotalamus terhadap makna-makna tersebut. Hasil yang diperoleh di area wernicke akan disimpan sebagai memori, lalu dikirimkan ke amigdala untuk ditentukan reaksi emosionalnya. Oleh karena itu, jika kita meresapi makna lantunan alqur'an, maka kita akan memperoleh ketenangan jiwa.

Berdasarkan tabel 4 memperlihatkan bahwa hasil uji 2 t dependent terapi musik klasik (mozart) dari hasil analisis "paired sample statistics" terlihat perbedaan nilai $\mathrm{p}$ yang dapat dilihat pada kolom sig (2-tailed). Jika nilai $\mathrm{p}<0,05$ maka kesimpulannya : ada perbedaan yang signifikan rata-rata pretest dan posttest anak tunalaras. 
Berdasarkan tabel 4 hasil pretest-postest 1 nilai $\mathrm{p}=0,783$ dan hasil pretest-postest 2 nilai $\mathrm{p}$ : 0,962 maka dapat disimpulkan hasil nilai $\mathrm{p}$ nya $>0,05$ artinya tidak ada perbedaan yang signifikan rata-rata pretest dan posttest ke 1 dan 2 anak tunalaras kelompok klasik Mozart, Sedangkan Hasil pretest-postest ke 3, 4 dan 5 nilai $\mathrm{p}=0,00$, Maka dapat disimpulkan hasil nilai $\mathrm{p}$ nya $<0,05$ artinya ada perbedaan yang signifikan rata-rata pretest dan posttest ke 3, 4 dan 5 pada perubahan emosi dan hubungan antar sebaya anak tunalaras kelompok klasik mozart.

Hasil penelitian ini selaras dengan penelitian Mohan, Thomas, (2020) yang menyatakan bahwa dalam penatalaksanaan seseorang dengan gangguan emosional seperti kecemasan, mudah marah, dan emosional yang tak menentu, dibutuhkan support system yang dapat memberikan stimulasi musik yang memiliki nada datar dan lembut seperti musik klasik, hal ini dikarenakan dengan mendengarkan suara musik klasik secara berulang lebih kurang tiga minggu mampu mempengaruhi proses emosional anak kearah yang lebih baik.

Selaras dengan hasil penelitian Rose et al., (2019) menyatakan bahwa perubahan perilaku dapat di evaluasi minimal pada minggu ke 3 (tiga), hal ini dikarenakan langkah perubahan perilaku terdiri atas 3 tahap yaitu tahap minggu 1 merupakan tahapan menanamkan pengalaman lalu dan saat ini untuk mempengaruhi pola pikir. Tahap minggu kedua merupakan tahapan internalisasi untuk menjadikan pengalaman sekarang menjadi suatu perilaku yang telah menjadi kebiasaan saat ini. Tahap minggu ketiga merupakan tahapan untuk mengubah pola sikap saat ini menjadi budaya baru.

Hasil penelitian ini selaras dengan beberapa hasil penelitian dimana pada kelompok intervensi musik didapatkan penurunan rerata emosional sebelum dan setelah intervensi sebesar 3,625, hal ini menunjukkan bahwa adanya penurunan skor emosional antara sebelum dan setelah intervensi terapi musik slowly (Ilari et al., 2020; Sharma \& Malhotra, 2019).

Berdasarkan tabel 5 memperlihatkan bahwa hasil uji 2 t dependent terapi musik murrotal (ar-rahman) hasil pretest-postest 1 nilai $\mathrm{p}$-value $=0,642$ dan hasil pretest-postest 2 nilai p-value : 0,177 maka dapat disimpulkan hasil nilai $\mathrm{p}$ nya $>0,05$ artinya tidak ada perbedaan yang signifikan rata-rata pretest dan posttest ke 1 dan 2 anak tunalaras kelompok murrotal ar-rahman sedangkan Hasil pretest-postest 3, 4 dan 5 nilai $p=0,000$. Maka dapat disimpulkan hasil nilai $\mathrm{p}$ nya $<0,05$ artinya ada perbedaan yang signifikan rata-rata pretest dan posttest ke 3,4 dan 5 pada perubahan emosi dan hubungan antar sebaya anak tunalaras kelompok murrotal ar-rahman.

Lantunan suara lembut Al-Qur'an yang diperdengarkan berulang kali oleh manusia mampu menurunkan hormon-hormon stres, mengaktifkan hormon endorphin alami, meningkatkan perasaan rileks, dan mengalihkan perhatian dari rasa takut, cemas dan tegang, memperbaiki sistem kimia tubuh sehingga menurunkan tekanan darah serta memperlambat pernafasan, detak jantung, denyut nadi, dan aktivitas gelombang otak sehingga menimbulkan ketenangan, mengendalikan emosi, mematangkan pemikiran dan membuat metabolisme tubuh menjadi lebih baik (Astuti et al., 2017).

Hasil penelitian ini selaras dengan penelitian Nisti et al., (2018) dimana rerata intervensi terapi murottal (surah Ar-Rahman) dengan hasil pretest dan posttest sebesar 5,06 dan 4,06 menunjukkan adanya penurunan skor perilaku emosional seperti kecemasan 
setelah mendapatkan terapi, artinya adanya perbedaan rerata yang signifikan skore emosional kecemasan sebelum dan setelah terapi murrotal (Ar-Rahman).

Berdasarkan tabel 6 Dari hasil penelitian setelah diberikan terapi musik pada kedua kelompok dapat dilihat pada hasil postest ke 5 antara terapi murrotal (Ar-Rahman) dan terapi music klasik (mozart) didapatkan nilai rata-rata 2,24 dan 9,06. Semakin kecil hasil nilai rerata pada kedua kelompok setelah intervensi menunjukkan semakin menurunnya kejadian tunalaras pada anak, dari hasil posttest murrotal ke 5 nilai reratanya lebih kecil dari klasik (mozart) artinya ada perbedaan yang signifikan rerata perubahan emosi dan hubungan antar sebaya anak tunalaras setelah diberikan intervensi terapi murrotal (ArRahman) skor tunalaras pada anak jauh lebih menurun dari pada terapi musik klasik (mozart).

Hasil penelitian yang dilakukan Malhotra tahun 2019 dan Purnama tahun 2016 menyatakan terdapat pengaruh musik klasik dalam mengurangi tingkat kekambuhan penderita skizofrenia di rumah (Malhotra et al., 2019; Purnama \& Rahmanisa, 2016).

Penelitian yang dilakukan oleh Anam (2018); Aziza et al., (2019); Nurqolbi, Kamaruddin, (2019); Park et al., (2018) dalam waktu penelitian tiga minggu pada kelompok intervensi didapatkan data responden berdasarkan gangguan emosional kepanikan, kecemasan, mengalami stress dan tekanan sebelum dan setelah intervensi jelas sekali bisa disimpulkan adanya perbedaan yang signifikan penurunan emosional pada kelompok yang diberikan intervensi dari pada kelompok kontrol.

Maka dari hasil penelitian ini, terapi musik murrotal (surah ar-rahman) sangat direkomendasikan untuk digunakan pada anak yang mengalami gangguan perilaku, emosional dan bermasalah dalam hubungan dengan teman sebaya.

\section{SIMPULAN}

Terdapat perbedaan yang signifikan pada perubahan emosi dan hubungan antar sebaya pada anak tunalaras usia sekolah antara terapi musik klasik (mozart) dan murrotal (Surah Ar-Rahman) dan terapi murrotal (Ar-Rahman) 6-7 kali lebih cepat menurunkan emosional dan memperbaiki hubungan antar sebaya anak tunalaras dibandingkan terapi musik klasik (mozart).

\section{SARAN}

Bagi orangtua yang memiliki anak tunalaras dianjurkan untuk sering mendengarkan terapi murrotal surah Ar-Rahman kepada anaknya terutama diwaktu malam menjelang tidur karena terbukti signifikan lebih efektif menurunkan emosional pada anak tunalaras serta dianjurkan kepada para orangtua dan keluarga untuk bersama-sama menemani anaknya mendengarkannya murrotal tersebut agar supaya hubungan antar keluarga semakin erat.

Untuk Perawat komunitas dan Rumah sakit dapat memodifikasi intervensi relaxsasi anak tunalaras yang sedang dirawat sehingga diharapkan mampu menenangkan emosional anak, mendistraksi mengurangi rasa sakit, sehingga dapat membantu perkembangan perilaku dan emosional anak sakit secara optimal sebagai bentuk peningkatan mutu pelayanan keperawatan anak 


\section{DAFTAR PUSTAKA}

Anam, A. (2018). Pengaruh Psychoreligius Care: Mendengarkan Murotal Al-Quran Dengan Irama Nahawand terhadap Penurunan Tingkat Kecemasan Pada Lansia di UPTD Griya Werdha Jambangan Kota Surabaya. Universitas Airlangga

Arfi, N., Alim, F., \& Azmi, S. A. (2019). Parental Handling Measures among Physically 57 Challenged Children and Normal Children: A Comparative Study. Delhi Psychiatric Journal, 22(1), 57-62

Ariffiani, G. (2017). Identifikasi Perilaku Sosial Siswa Tunalaras di SLB E Prayuwana $\begin{array}{lllll}\text { Yogyakarta. } \quad \text { Universitas Negeri } & \text { Yogyakarta, }\end{array}$ https://doi.org/10.1017/CBO9781107415324.004

Astuti, A., Suryono, S., Widyawati, M. N., Suwondo, A., \& Mardiyono, M. (2017). Effect of Audio Therapy Using Al-Qur'an Murrotal on Behavior Development in Children with Autism. Belitung Nursing Journal, 3(5), 470-477. https://doi.org/10.33546/bnj.189

Aziza, C. N., Bakar, A., \& Ulfiana, E. (2019). Pengaruh Murottal Al-Quran terhadap Pengendalian Emosi (Anger Management) dan Tekanan Darah pada Penderita Hipertensi. Journal Keperawatan Komunitas, 8(1), 23-28

Burhaein, E. (2017). Optimization of Game Character Education Based on Traditional Physical Education of Children With Behaviour and Emotional Problemsthrough Learning Model Quantum Learning (Neuro Learning and Psychology Learning). Proceeding International Conferencere Adri, IV, 27

Cabaço, S. R., Caldeira, S., Vieira, M., \& Rodgers, B. (2018). Spiritual Coping: A Focus of New Nursing Diagnoses. International Journal of Nursing Knowledge, 29(3), 156164. https://doi.org/10.1111/2047-3095.12171

Fatima, S., Sharif, S., \& Khalid, I. (2018). How Does Religiosity Enhance Psychological Well-Being? Roles of Self-Efficacy and Perceived Social Support. Psychology of Religion and Spirituality, 10(2), 119-127. https://doi.org/10.1037/rel0000168

Ilari, B., Helfter, S., \& Huynh, T. (2020). Associations Between Musical Participation and Young Children's Prosocial Behaviors. Journal of Research in Music Education, 67(4), 399-412. https://doi.org/10.1177/0022429419878169

Kustriyani, M., Widyaningsih, T. S., \& Prasertyo, A. (2017). Hubungan Peer Group Support dengan Perilaku Memilih Jajanan Sehat pada Anak Usia Sekolah di Madrasah Ibtidaiyah (MI) Al-Mukmin Prawoto Kota Pati. Jurnal Unimus, 1(1), 334342

Malhotra, S., Khan, W., \& Bhatia, M. (2019). Gender Differences in Parenting Stress in Caregivers of Children with Intellectual Disability. Delhi Psychiatric Journal, 22(1), $68-71$

Mohan, A., \& Thomas, E. (2020). Effect of Background Music and the Cultural Preference to Music on Adolescents' Task Performance. International Journal of Adolescence and Youth, 25(1), 562-573. https://doi.org/10.1080/02673843.2019.1689368

Nisti, N., Andriyani, A., Annisa, A., \& Hartutik, H. (2018). Penerapan Distraksi Audio Murrotal Alqur'an Surat Ar-Rahman terhadap Penurunan Nyeri Pasien Post Sectio Caesarea [Stikes 'Aisyiyah]. http://eprints.stikes-aisyiyah.ac.id/id/eprint/891 
Nogaj, A. A. (2020). Emotional Intelligence and Strategies for Coping with Stress among Music School Students in the Context of Visual Art and General Education Students. Journal of Research in Music Education, 68(1), 78-96. https://doi.org/10.1177/0022429420901513

Nuhan, K., Astuti, T., \& Murhan, A. (2018). Pengaruh Murottal Al-Qur'an terhadap Intensitas Nyeri pada Pasien Post Operasi Sectio Caesarea. Jurnal Ilmiah Keperawatan Sai Betik, 14(1), 91. https://doi.org/10.26630/jkep.v14i1.1014

Nurqolbi, S., \& Kamaruddin, M. (2019). Pengaruh Terapi Murottal Al-Qur'an terhadap Tingkat Kecemasan Ibu Menghadapi Persalinan di Rumah Sakit Siti Khadijah III Makassar. Medika Alkhairaat: Jurnal Penelitian Kedokteran dan Kesehatan, 1(2), 65-69. http://jurnal.fkunisa.ac.id/index.php/MA/article/view/30

Park, C. L., Holt, C. L., Le, D., Christie, J., \& Williams, B. R. (2018). Positive and Negative Religious Coping Styles as Prospective Predictors of Well-Being in African Americans. Psychology of Religion and Spirituality, 10(4), 318-326. https://doi.org/10.1037/rel0000124

Purnama, D. M. W., \& Rahmanisa, R. (2016). Pengaruh Musik Klasik dalam Mengurangi Tingkat Kekambuhan Penderita Skizofrenia di Rumah. Majority, 5(4), 50-54

Putri, M. (2018). Hubungan Kepercayaan Diri dan Dukungan Teman Sebaya dengan Jenis Perilaku Bullying. Menara Ilmu, 7(8), 107-116. https://doi.org/https://doi.org/10.33559/mi.v12i8.872

Rose, D., Bartoli, J. A., \& Heaton, P. (2019). Measuring the Impact of Musical Learning on Cognitive, Behavioural and Socio-Emotional Wellbeing Development in Children. Psychology of Music, 47(2), 284-303. https://doi.org/10.1177/0305735617744887

Sharma, S., \& Malhotra, S. (2019). A Comparative Study of Stress Level in Siblings of Children with and without Disability. Delhi Psychiatric Journal, 22(1), 77-81

Sufriani, \& Sari, E. P. (2017). Faktor yang Mempengaruhi Bullying pada Anak Usia Sekolah Banda Aceh. Idea Nursing Journal

Sukeri, M. S. (2018). Terapi Musik Dzikir untuk Relaksasi Stres Seorang Anak Jalanan di UPTD Kampung Anak Negeri Surabaya. http://uinsurabaya.doc.160445485.pdf

Yang, M., He, H., Duan, M., Chen, X., Chang, X., Lai, Y., Li, J., Liu, T., Luo, C., \& Yao, D. (2018). The Effects of Music Intervention on Functional Connectivity Strength of the Brain in Schizophrenia. Neural Plasticity, 2018, 1-10. https://doi.org/10.1155/2018/2821832 